\title{
Mechanical milling assisted synthesis and electrochemical performance of high capacity $\mathrm{LiFeBO}_{3}$ for Lithium Batteries
}

\author{
Musa A. Cambaz ${ }^{1}$, M. Anji Reddy ${ }^{1}$, Vinayan B.P. ${ }^{1}$, Ralf Witte ${ }^{2}$, Alexander Pohl ${ }^{2}$, Xiaoke Mu ${ }^{1}$, \\ Venkata Sai Kiran Chakravadhanula ${ }^{1,2}$, Christian Kübel ${ }^{1,2}$, Maximilian Fichtner ${ }^{1,2, *}$ \\ ${ }^{1}$ Helmholtz Institute Ulm for Electrochemical Energy Storage (HIU), Helmholtzstraße 11, 89081 \\ Ulm, Germany, ${ }^{2}$ Institute of Nanotechnology, Karlsruhe Institute of Technology (KIT), P.O. Box \\ 3640, 76021 Karlsruhe, Germany, *e-mail: maximillian.fichtner@kit.edu
}

Keywords: $\mathrm{LiFeBO}_{3}$, polyanion, lithium diffusion coefficient; lithium batteries, Mössbauer study, cathode

\begin{abstract}
Borate chemistry offers attractive features for iron based polyanionic compounds. For battery applications, lithium iron borate has been proposed as cathode material because it has the lightest polyanionic framework that offers a high theoretical capacity. Moreover, it shows promising characteristics with an element combination that is favourable in terms of sustainability, toxicity, and costs. However, the system is also associated with a challenging chemistry, which is the major reason for the slow progress in its further development as a battery material. The two major challenges in the synthesis of $\mathrm{LiFeBO}_{3}$ are in obtaining phase purity and high electrochemical activity. Herein, we report a facile and scalable synthesis strategy for highly pure and electrochemically active $\mathrm{LiFeBO}_{3}$ by circumventing stability issues related to $\mathrm{Fe}^{2+}$ oxidation state by the right choice of the precursor and experimental conditions. Additionally we carried out a Mössbauer spectroscopic study of electrochemical charged and charged-discharged $\mathrm{LiFeBO}_{3}$ and reported a lithium diffusion coefficient of $5.56 \times 10^{-14} \mathrm{~cm}^{2} \mathrm{~s}^{-1}$ for the first time.
\end{abstract}

\section{Introduction}

The demand for new sustainable, environmentally friendly, cheap, and safe electrode materials as well as the report by Padhi et al ${ }^{1}$ about $\mathrm{LiFePO}_{4}$ as viable cathode has attracted increasing interest to Iron-based polyanionic framework compounds for lithium- 
ion batteries. In the search for materials with higher energy densities focus has been devoted on materials with high redox potentials, low weight framework compounds associated with high capacities and compounds with the ability to store more than one electron. ${ }^{2-4}$ In this regard lithium metal borates ${ }^{5-9}\left(\mathrm{LiMBO}_{3}\right)$ occupy a special position among the family of polyanions, having the lowest-weight framework $\left(\mathrm{BO}_{3}{ }^{3-}<\mathrm{SiO}_{4}{ }^{2-}<\right.$ $\mathrm{PO}_{4}{ }^{3-}<\mathrm{SO}_{4}{ }^{2-}$ ) and delivering therefore the highest theoretical capacity for the one electron $\mathrm{Fe}^{3+} / \mathrm{Fe}^{2+}$ redox reaction with $220 \mathrm{mAh} \mathrm{g}{ }^{-1}$. This capacity in combination with an electro motive force (EMF) of $\sim 2.8 \mathrm{~V}$ offers the possibility of achieving higher energy density $\left(616 \mathrm{Wh} \mathrm{kg}^{-1}\right)$ relative to the commercialised LiFePO4 (585 $\left.\mathrm{Wh} \mathrm{kg}^{-1}\right){ }^{10,11}$ However, an intrinsic drawback of $\mathrm{LiFeBO}_{3}$ is its poor electrical conductivity associated with a higher polarization. Moreover, first-principle calculations suggest a one-dimensional lithium diffusion path, which is known to be sensitive for defects. ${ }^{12,13}$ These obstacles, which are determining the electrochemical performance could be overcome by introducing a conductive carbon coating and downsizing of the material to shorten the $\mathrm{Li}^{+}$diffusion path $^{14}$. Since the first work of Legagneur ${ }^{15}$ in 2001 on both the synthesis and structural characterization of $\mathrm{LiFeBO}_{3}$ considerable efforts have been undertaken to optimize the material in order to improve its reversible capacity. Attempts were made to reduce the particle size, to develop a homogenous carbon coating and to improve the electrochemical performance. In this respect only a few reports have been published. ${ }^{16-18}$ Common for all of them was the poor electrochemical performance/activity with low capacity accompanied with a large polarization and no well-defined plateau, involving reactions occurring at voltages below $1.8 \mathrm{~V}$ that are associated with a contribution to the capacity. The first breakthrough in electrochemically active material with access to a reversible room temperature activity of around $190 \mathrm{mAh} \mathrm{g}^{-1}$ was achieved by Yamada et al. in $2010^{19}$. Being aware of surface degradation issues for material with potential lower than $3.0 \mathrm{~V}$, Yamada et al. took precaution by careful preparation and control of the atmosphere throughout the synthesis process. A comparable result with a wider cycling range $(\sim 30$ $\mathrm{mAh} / \mathrm{g}$ coming from discharge below 1,5 V) was achieved by Bo et al. who succeeded in the preparation of good capacity $\mathrm{LiFeBO}_{3}$ by using reducing gas atmosphere $\mathrm{H}_{2} / \mathrm{N}_{2}(5 / 95)$ to prevent surface oxidation of the $\mathrm{Fe}^{2+}$ beeing identified as an origin for the capacity degradation $^{20}$. Further emphasis was addressed to the carbon coating and particle size which have been regarded to be crucial for good electrochemical performance. 
Approximately 10 weight percent of impurities were found in both cases with $\mathrm{Fe}_{3} \mathrm{BO}_{5}$ (mixed valence compound of $\mathrm{Fe}^{2+}$ and $\mathrm{Fe}^{3+}$ ) as major phase. A better control over the iron oxidation state, which was shown to be the key for the synthesis of highly pure $\mathrm{LiFeBO}_{3}$,

was achieved by Tao et al. ${ }^{21,22}$ who used a $\mathrm{CO} / \mathrm{CO}_{2}$ gas flow as a mild reduction agent to supress the oxidation of $\mathrm{Fe}^{2+}$. In the cycling range of 2.0-4.5 $\mathrm{V}$ for elevated temperatures $\left(55^{\circ} \mathrm{C}\right)$ they reported a reversible capacity of $130 \mathrm{mAh} \mathrm{g}^{-1}$ for a cut-off voltage of $2.0 \mathrm{~V}$. For deeper discharge up to $1.5 \mathrm{~V}$, which resulted in a capacity of $210 \mathrm{mAh} \mathrm{g}^{-1}$ they observed an irregular increase in the specific capacity for higher cycle numbers and even went beyond the theoretical capacity, which might be attributed to the higher reactivity of the electrolyte for elevated temperatures at low voltage. Besides this classic sold state (ceramic) methods noteworthy to mention are solution combustion synthesis ${ }^{23}$ spraydrying and carbothermal methods. ${ }^{24}$

From earlier reports it is clear that in order to achieve high capacities and good electrochemical activity highly pure and nanocrystalline material is needed According to these previous reports the main synthetic challenges, are on the one hand the stabilization of the $\mathrm{Fe}^{2+}$ oxidation state and on the other hand the introduction of a carbon coating to keep the particle size small and to enhance electrical conductivity.

A carbon coating can either be achieved by mixing the carbon prior to the sintering process or by pyrolysis of an organic precursor. For the latter the challenge is to establish a well-controlled reducing gas atmosphere to stabilize the $\mathrm{Fe}^{2+}$ oxidation state in order to compensate partial oxidation. Our approach and a possible solution for this issue were to circumvent these problems by using $\mathrm{FeO}$ (wüstite) as iron precursor and by mixing carbon prior to the sintering. Since the iron is introduced in the desired oxidation state, $\mathrm{LiFeBO}_{3}$ can be formed directly by circumventing the formation of stable secondary phases and moisture, which can cause unwanted oxidation of the iron state. Herein, we demonstrate a facile method to synthesize highly pure and electrochemically active $\mathrm{LiFeBO}_{3}$ by high energetic mechanical alloying under inert gas atmosphere.

\section{Experimental section}

\section{Synthesis of $\mathrm{LiFeBO}_{3}$ carbon composite}

A simple process was chosen to synthesize $\mathrm{LiFeBO}_{3}$ through a conventional solid-state reaction at room temperature. Therefore, iron(II)oxide (FeO Aldrich $99.9 \%$ ) was ball 
milled with a slight excess of $10 \mathrm{wt} \%$ lithium meta borate $\mathrm{LiBO}_{2}$ (Alfa Aesar 99.9\%) together with 20 wt\% conductive carbon black agent C-nergy Super C65 (Imerys Graphite \& Carbon) for $15 \mathrm{~h}$ using a Fritsch P6 planetary ball mill with $80 \mathrm{~mL}$ silicon nitride vial and silicon nitride balls, at a ball to powder ratio of 15:1. After ball milling, the product powder was transferred into a corundum crucible and was sintered at $600{ }^{\circ} \mathrm{C}$ for $1 \mathrm{~h}$ under Ar flow. Prolonged exposure to heat led to a rise of the $\mathrm{Fe}_{3} \mathrm{BO}_{5}$ content which was an impurity in the product. All steps were carried out under moisture and air-free conditions which was of utmost importance.

\section{Structural analysis}

\section{X-Ray diffraction (XRD)}

Powder XRD data were collected on a STOE Stadi P diffractometer with Mo $\mathrm{K}_{\alpha 1}(\lambda=$ $0.7093 \AA$ A) using Debye-Scherrer geometry. The powder samples were sealed in quartz capillary $(0.5 \mathrm{~mm}$ in diameter) under an argon atmosphere.

\section{${ }^{57} \mathrm{Fe}$ Mössbauer spectroscopy}

Mössbauer spectra were recorded using a constant acceleration-type spectrometer in transmission geometry with a moving source of ${ }^{57} \mathrm{Co}$ in a $\mathrm{Rh}$ matrix. The samples were sealed in a plastic bag inside an argon filled glove box using a lava V.300 vacuum sealer. Isomer shifts $(I S)$ are given relative to bcc-Fe at room temperature. The data is fitted using the WinNormos software package (Wissel Company, R. A. Brand).

\section{Transmission electron microscopy (TEM) characterization}

TEM measurements were performed using an aberration-corrected (image) FEI Titan 80300 operated at $80 \mathrm{kV}$ acceleration voltage, equipped with a Gatan US1000 CCD camera and a Gatan Tridem 863 energy filter. The samples were transferred under inert conditions (Argon) from the glove box to the microscope using Gatan vacuum transfer holder minimizing the possible reaction between the sample and air (oxygen and moisture). The TEM was operated under controlled low-dose conditions to minimize electron beam damage of the sample.

\section{Electrochemical characterization}


Electrochemical tests were carried out in Swagelok-type cell versus lithium. Electrode slurries were made by mechanical mixing of $90 \mathrm{wt} \%$ composite and $10 \mathrm{wt} \%$ polyviniylidene difluoride (PVDF) binder with N-methyl-2-pyrrolidone (NMP) as solvent using a Fritsch P6 planetary ball mill for $4 \mathrm{~h}$ with $200 \mathrm{rpm}$ and a ball to powder ratio of 7:1. Approximately $3 \mathrm{mg}$ of material was casted on a stainless steel current collector and dried at $120{ }^{\circ} \mathrm{C}$ for $12 \mathrm{~h}$ under vacuum. Li foil was used as counter electrode. LP30 from BASF ( $1 \mathrm{M} \mathrm{LiPF}_{6}$ in 1:1 volume ratio of ethylene carbonate/ dimethyl carbonate was used as electrolyte. For cycling measurement cells were placed in an incubator at $25^{\circ} \mathrm{C}$ or $45^{\circ} \mathrm{C}$. Galvanostatic charge-discharge experiments were conducted using Arbin electrochemical workstation. Cylic voltammetry (CV) measurements were conducted with a Biologic VMP-3.

\section{Results and discussion}

The synthesis methodology followed for $\mathrm{LiFeBO}_{3}$ carbon composite includes two following steps: i) intimate mixing of the precursors together with a conductive carbon additive and ii) sintering for a short period of time (1h) at $600 \mathrm{C}$ under Ar gas flow. The Rietveld refined powder $\mathrm{X}$-ray diffraction pattern of the pristine $\mathrm{LiFeBO}_{3}$ sample is shown in figure $1 \mathrm{a}$ ). The reflections could be indexed using a monoclinic unit cell with refined lattice parameters of $\mathrm{a}=5.1608(3) \AA, \mathrm{b}=8.9183(6) \AA, \mathrm{c}=10.1598(4) \AA$ and $\beta=$ $91.407(5)^{\circ}\left(\mathrm{V}=467.47(5) \AA^{3}\right.$, space group $\left.\mathrm{C} 2 / \mathrm{c}, \mathrm{Rwp}=5.17 \%\right)$. The lattice parameters are in good agreement with the structure of $\mathrm{LiFeBO}_{3}$ published in the literature ${ }^{21}$. Around $1 \mathrm{wt} \% \mathrm{Fe}_{3} \mathrm{C}$ is found in the sample. Furthermore a small amount of martensitic $\mathrm{Fe}-\mathrm{C}$ solid solution with low carbon content (3.1(2) wt.\%) is present in the sample, which was difficult to differentitate from elemental $\alpha-\mathrm{Fe}$ by XRD, but could be identfied by Mössbauer spectroscopy, see below. Additionally there was also a small amount of $\mathrm{Fe}_{3} \mathrm{C}$ (<1wt.\%, 99017 ICSD) present, which could also be identified by Mössbauer spectroscopy. FeO being metastable and tending to decompose during ball milling and annealing steps is possibly the reason for the impurities ${ }^{25}$ observed. 

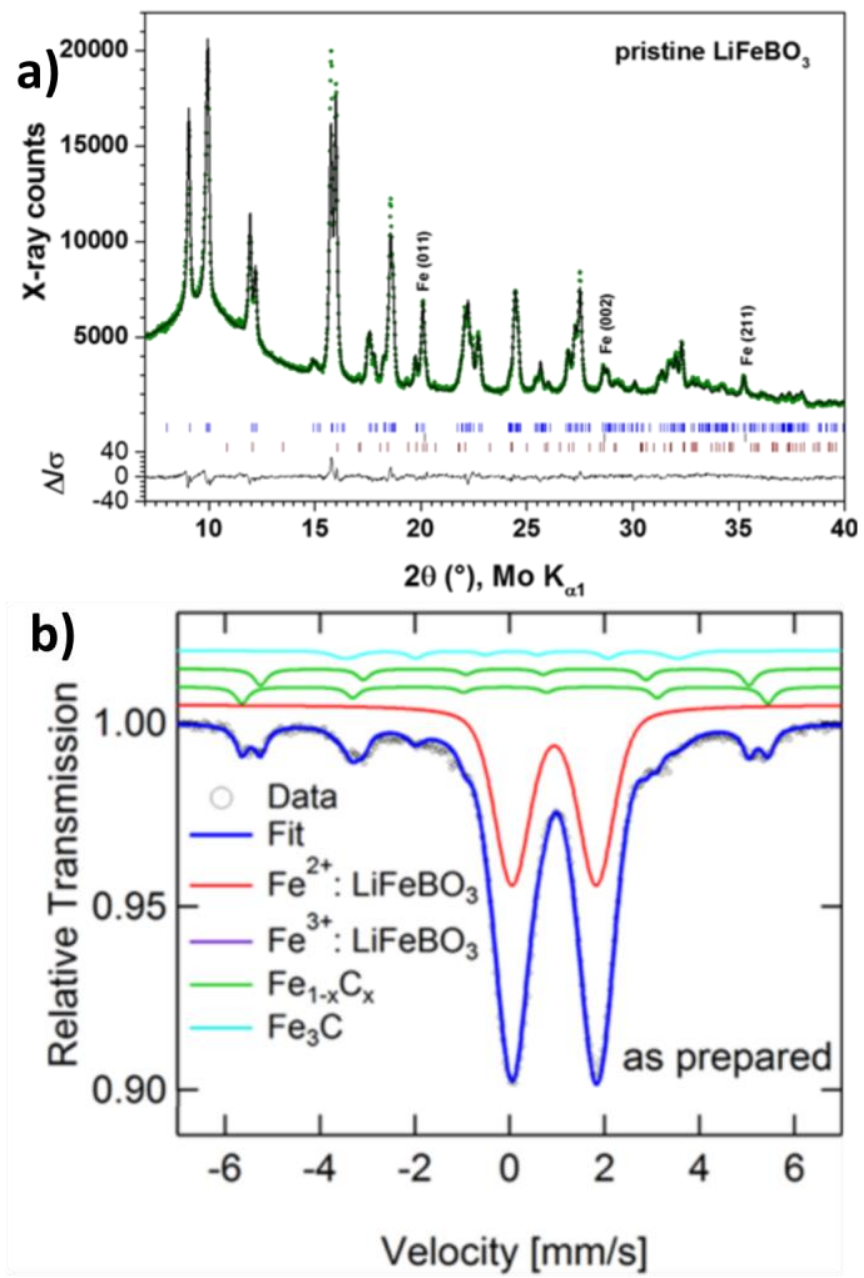

Figure 1. a) Rietveld refinement of the XRD pattern of pristine $\mathrm{LiFeBO}_{3} \cdot(\lambda=0.7093 \AA)$. The green dots correspond to experimental data, the black line is the calculated fit and the tick marks are at the Bragg positions of $\mathrm{LiFeBO}_{3}$ (blue), $\mathrm{Fe}$ (black) and $\mathrm{Fe}_{3} \mathrm{C}$ (brown) phases, as indicated b) Mössbauer spectra of the pristine sample respectively quadrupole doublet is attributed to the $\mathrm{Fe}^{2+}$ species in the $\mathrm{LiFeBO}_{3}$ structure, the three sextets are assigned to various $\mathrm{Fe}-\mathrm{C}$ compounds.

The Mössbauer spectrum of the as prepared sample is shown in figure $1 \mathrm{~b}$ ). The spectrum can be reproduced with four sub spectra. The main component originates from the $\mathrm{LiFeBO}_{3}$ and is a doublet with an isomer shift (IS) and quadrupole splitting (QS) typical for ferrous $\mathrm{Fe}$-ions in a trigonal-bipyramidal $\mathrm{FeO}_{5}$-site. The doublet is similar to the spectrum reported for $\mathrm{LiFeBO}_{3}{ }^{19}$ Additionally three magnetic sextets with minor intensity were observed, two of them can be most likely attributed to a martensitic Fe-C solid solution with low carbon content and while the third is a $\mathrm{Fe}_{3} \mathrm{C}$ cementite phase with a 
quantitity of $1 \mathrm{wt} \% \mathrm{Fe}_{3} \mathrm{C}$ in accordance with the Mössbauer spectra. Various Fe-C compounds are known to form during ball milling of $\mathrm{Fe}$ and graphite ${ }^{26}$.

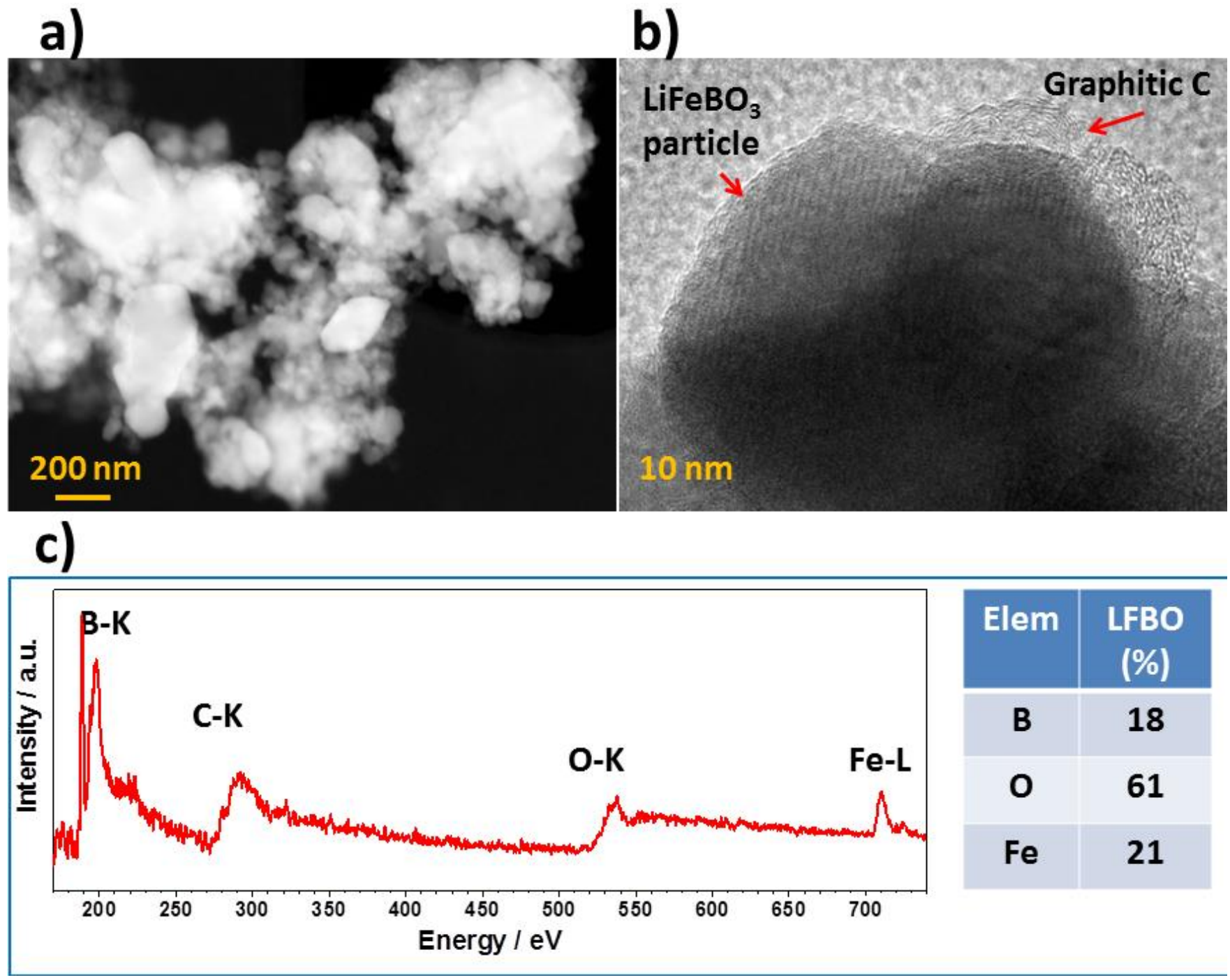

Figure 2. (a) STEM-HAADF overview image and (b) HRTEM micrograph of the as-prepared sample. (c) EELS spectrum (left) of the as-prepared sample and the elemental quantification results (right) calculated from the spectrum (left).

The scanning electron micrograph of the carbon coated $\mathrm{LiFeBO}_{3}$ is shown in figure $\mathrm{S} 1$ and is illustrating the overall bulk morphology of the $\mathrm{LiFeBO}_{3}$ carbon composite. The obtained powder contained primary particles in form of agglomerates as large as $\sim 0.8 \mu \mathrm{m}$ consisting of individual 20 to $100 \mathrm{~nm}$ particles which do not have a uniform geometric shape and homogenous particle size distribution and is typical for mechanomilled 
samples $^{27}$. Transmission electron microscope (TEM) studies were carried out to investigate the in-depth morphology of the $\mathrm{LiFeBO}_{3}$ carbon composite and are shown in. Figure 2 a) shows a STEM-HAADF overview image of the morphology in the as-prepared sample in which the size of the ball milled nanoparticles is between $50-200 \mathrm{~nm}$. The HRTEM micrograph in figure $2 \mathrm{~b}$ shows a typical $\mathrm{LiFeBO}_{3}$ particle, in which the graphitic onion-formed layers are aggregated around the $\mathrm{LiFeBO}_{3}$ particle. EELS spectrum of the as-prepared sample in figure 2 c) (left) exhibits the pronounced Borate-K edge, Oxygen- $K$ and Iron-K edge signals as well as the Carbon-K edge for the graphitic additives. Elementary quantification in figure $2 \mathrm{c}$ ) (right) shows $\mathrm{Fe}: \mathrm{B}: \mathrm{O}=1: 1: 3$ agreeing well with the chemical composition of $\mathrm{LiFeBO}_{3}$. 


\section{Electrochemical characterization}
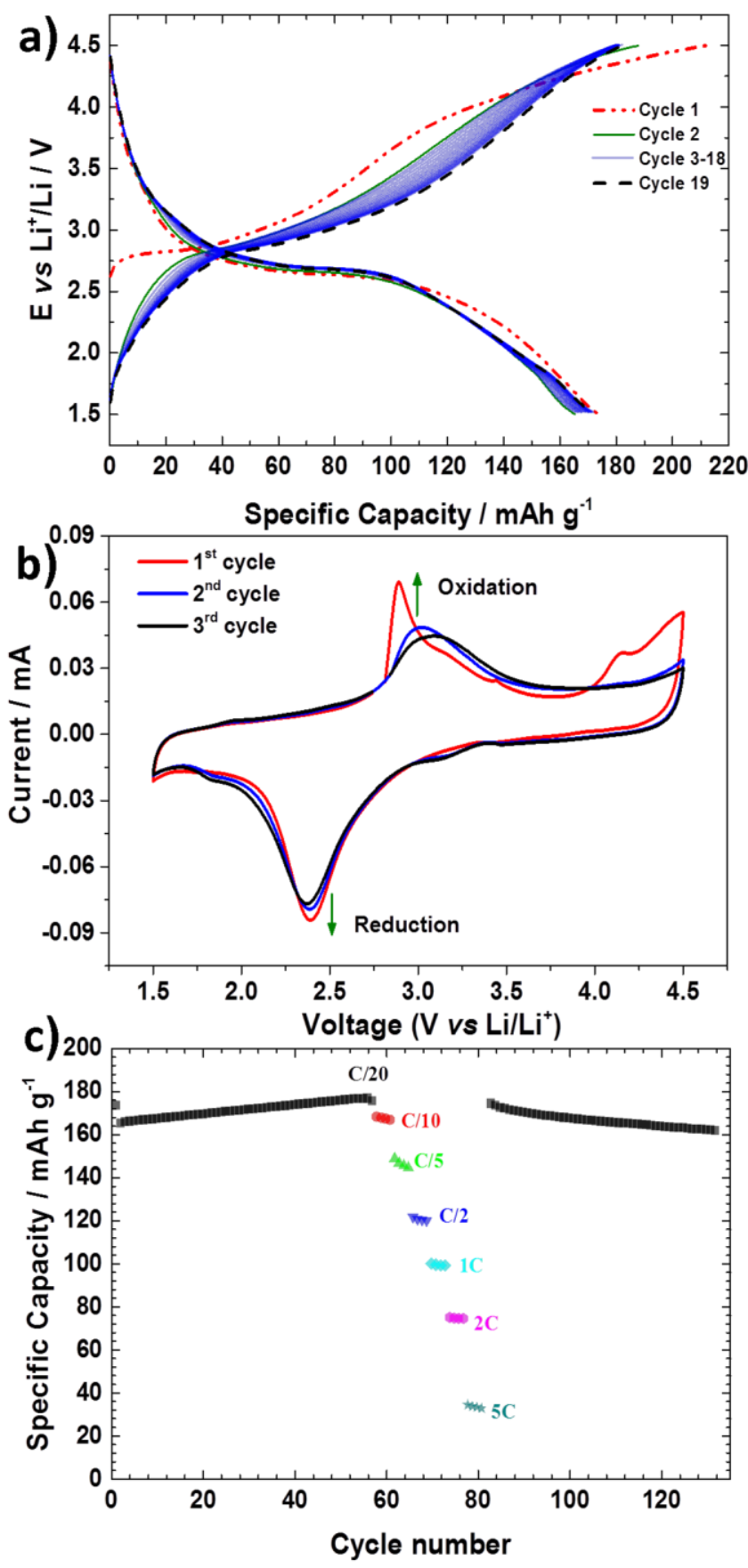

Figure 3. (a) Cyclic voltammetry curve of $\mathrm{LiFeBO}_{3}$ carbon composite at a scan rate with of 0.1 mVs-1 (b) Galvanostatic voltage-capacity curves of $\mathrm{LiFeBO}_{3}$ carbon composite cycled between $1.5 \sim 4.5 \mathrm{~V}$ at a rate of C/20 for RT (c) Cycling performance with an intermediate rate capability test for various cycled between $1.5 \sim 4.5 \mathrm{~V}$. 
Figure 3 a) shows the typical electrochemical charge discharge profiles of $\mathrm{LiFeBO}_{3} / \mathrm{C}$ composite versus lithium obtained at $\mathrm{C} / 20$ rate at $25^{\circ} \mathrm{C}$ within the voltage range of $1.5 \mathrm{~V}$ $4.5 \mathrm{~V}$. The first charge capacity was $210 \mathrm{mAh} / \mathrm{g}^{-1}$ and corresponds to the extraction of 0.9 lithium, the first discharge capacity was $172 \mathrm{mAh} / \mathrm{g}^{-1}$ and corresponds to the reinsertion of $0.78 \mathrm{Li}$. Capacity loss of $40 \mathrm{mAh} / \mathrm{g}^{-1}$ was observed in the first cycle. The discharge profile for the $\mathrm{Fe}^{3+} / \mathrm{Fe}^{2+}$ is giving a sloping solid solution like behaviour with a fracture of a plateau around $2.7 \mathrm{~V}$. The subsequent charge/discharge curves were showing lower polarization and were found to superimpose for prolonged cycling indicating good capacity retention. For higher cycle numbers a change in the slope with an increase in the contribution to the overall capacity was observed for the low voltage regime at around 1.8 $\mathrm{V}$, which can be assigned to degraded $\mathrm{LiFeBO}_{3}$ phase discussed below ${ }^{28}$

Figure $3 \mathrm{~b}$ ) depicts the corresponding cyclic voltammetry curves for the $\mathrm{LiFeBO}_{3} / \mathrm{C}$ composite versus lithium. In the $\mathrm{CV}$, for the first cycle a sharp anodic peak is observed at $\sim 2.85 \mathrm{~V}$, which might be attributed to the extraction of lithium and irreversible peaks for $3.4 \mathrm{~V}$ and $4.2 \mathrm{~V}$, likelydue to irreversible reactions. The first cathodic peak is broad and centred at $2.4 \mathrm{~V}$ and a smaller peak at $1.8 \mathrm{~V}$, which possibly is due to the lithium reintercalation into the structure. Upon further cycling overall the curves become broader and tend to overlap with an anodic peak for $3.2 \mathrm{~V}$ identifiable and a slight increase for continuing cycling for the cathodic peak at $1.8 \mathrm{~V}$. This observation fits well with the change in the discharge profile for the lower voltage regime $<2.0 \mathrm{~V}$.

Figure $3 \mathrm{c}$ ) shows the cycling behaviour of $\mathrm{LiFeBO}_{3}$ carbon composite at $\mathrm{C} / 20$ rate within the voltage range of $1.5 \mathrm{~V}-4.5 \mathrm{~V}$ with an intermediate rate capability test. A steady increase is observed in the capacity for the first 58 cycles, which is possibly attributed to the lower voltage process explained in later part. Between 59 to 82 cycles a rate capability test was applied for different current densities. For $0.1 \mathrm{C}, 1 \mathrm{C}$ and $5 \mathrm{C}$ the composite delivered a reversible capacity of $167 \mathrm{mAh} \mathrm{g}^{-1}, 99 \mathrm{mAh} \mathrm{g}^{-1}$ and $33 \mathrm{mAh} \mathrm{g}^{-1}$ respectively. After the C-rate test a slow decay in the capacity was observed stabilizing at around 161 $\mathrm{mAh} \mathrm{g}^{-1}$.

Investigations of Bo et al. revealed that the contribution of the low voltage processes ( $1.8 \mathrm{~V}$ ) can be ascribed to degraded $\mathrm{LiFeBO}_{3}$ phase, which has a reduced thermodynamic 
potential and can be cycled reversibly ${ }^{28}$. This contribution probably explains the increase in capacity for the initial 60 cycles and the slope in the low voltage region for prolonged cycles.

The strong current density dependence together with the higher polarization is hinting a kinetic limitation of the $\mathrm{LiFeBO}_{3}$ for which current densities and cell temperature are crucial factors. In order to achieve an improvement in the accesible reversible capacity of the $\mathrm{LiFeBO}_{3}$, a study for elevated temperatures have been performed. Figure 4 a) is showing the comparison of discharge profiles of $\mathrm{LiFeBO}_{3}$ carbon composite for $\mathrm{C} / 20$ in the range of $1.5 \mathrm{~V}-4.5 \mathrm{~V}$ at $45{ }^{\circ} \mathrm{C}$ and for RT against lithium. For elevated temperatures the accesible capacity for the first discharge increased from $173 \mathrm{mAh} \mathrm{g}^{-1}$ to $191 \mathrm{mAh} \mathrm{g}^{-1}$, which is likely due to temperature activation without any obvious change in the chargedischarge profile. Figure 4 a) is showing the cycling performance for $\mathrm{LiFeBO}_{3}$ carbon composite for $\mathrm{C} / 20$ in the range of $1.5 \mathrm{~V}-4.5 \mathrm{~V}$ at the temperature $\mathrm{T}=45{ }^{\circ} \mathrm{C}$ against lithium. For the elevated temperatures the charge capacity is increased significantly and shows therefore lower coulombic efficiency, which is probably due to the reactivity with the electrolyte and is also observed elsewhere. ${ }^{17,22}$ 

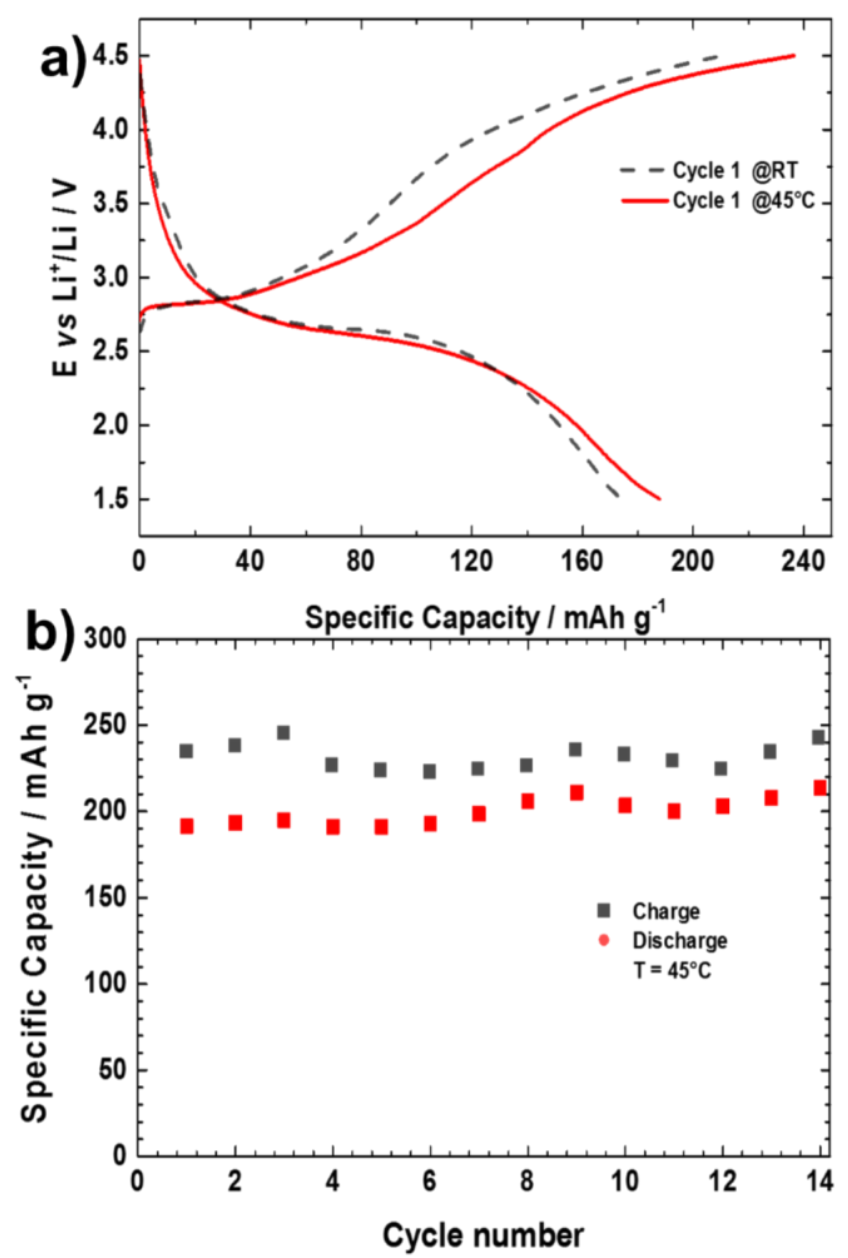

Figure 4. (a) Galvanostatic voltage-capacity curves of $\mathrm{LiFeBO}_{3}$ carbon composite cycled between $1.5 \sim 4.5 \mathrm{~V}$ at a rate of $\mathrm{C} / 20$ for $45{ }^{\circ} \mathrm{C}$ (b) Cycling performance for $\mathrm{C} / 20$ rate cycled between $1.5 \sim 4.5 \mathrm{~V}$

In order to evaluate kinetic properties of the $\mathrm{LiFeBO}_{3}$ carbon composite cyclic voltammetry $(\mathrm{CV})$ at various scan rates in the range of $0.05-0.5 \mathrm{mV} \mathrm{s}^{-1}$ has been carried out to obtain the lithium ion diffusivity. Figure 5 a) shows that oxidation/reduction peak separation and peak current intensity are increasing with respect to the increase in scan rate. Oxidation/reduction peak currents $\left(\mathrm{I}_{\mathrm{p}}\right)$ are proportional to the square root of the scan rate $(v)$ for semi-infinite linear diffusion systems and hence the diffusion coefficient (D) can be calculated using Randles-Sevcik equation (1) at room temperature $\left(25^{\circ} \mathrm{C}\right) .{ }^{29,30}$ $I_{p}=2.69 \times 10^{5} A C D^{0.5} n^{1.5} v^{0.5}$ 
Where ' $\mathrm{A}$ ' is the effective area of $\mathrm{LiFeBO}_{3}$ electrode within the electrolyte solution. BET surface area of $\mathrm{LiFeBO}_{3}\left(178.3 \mathrm{~m}^{2} \mathrm{~g}^{-1}\right.$, Figure S2) was taken as the effective area ' $\mathrm{A}$ ' in the present case. ' $n$ ' is the number of electrons involved in the redox process $(n=1), v$ is the voltage scan rate $\left(\mathrm{V} \mathrm{s}^{\text {' }}\right.$ $\left.{ }^{1}\right)$ and $D$ is the diffusion coefficient of $\mathrm{Li}$ in the electrode $\left(\mathrm{cm}^{2} \mathrm{~s}^{-1}\right)$. C is the $\mathrm{Li}$ concentration of $\mathrm{LiFeBO}_{3}$ material, with a density of $3.46 \mathrm{~g} \mathrm{~cm}^{-3}$ and molar mass of $121.5972 \mathrm{~g} \mathrm{~mol}^{-1}$, for which the corresponding Li concentration ' $\mathrm{C}$ ' is $0.028454 \mathrm{~mol} \mathrm{~cm}^{-3} .{ }^{19}$ Figure $5 \mathrm{~b}$ ) shows the two fitting lines correspond to the anodic and cathodic peak currents $\left(\mathrm{I}_{\mathrm{p}}\right)$ with respect to the square root of the scanning rate ' $v$ ' and the diffusion coefficient $\mathrm{D}$ can be calculated from the slope of these fitting lines. The calculated litihum diffusion coefficient for $\mathrm{LiFeBO}_{3}$ was $5.53 \times 10^{-14}$ and $5.56 \times$ $10^{-14} \mathrm{~cm}^{2} \mathrm{~s}^{-1}$ for the anodic and cathodic reactions, respectively. In comparison with the $\mathrm{Li}_{2} \mathrm{FeSiO}_{4}{ }^{31}$ with diffusion coefficients in the order of $10^{-13}-10^{-12}$ and similar rate capability characteristics the slower lithium diffusion implies the lower rate capability of the $\mathrm{LiFeBO}_{3}$.
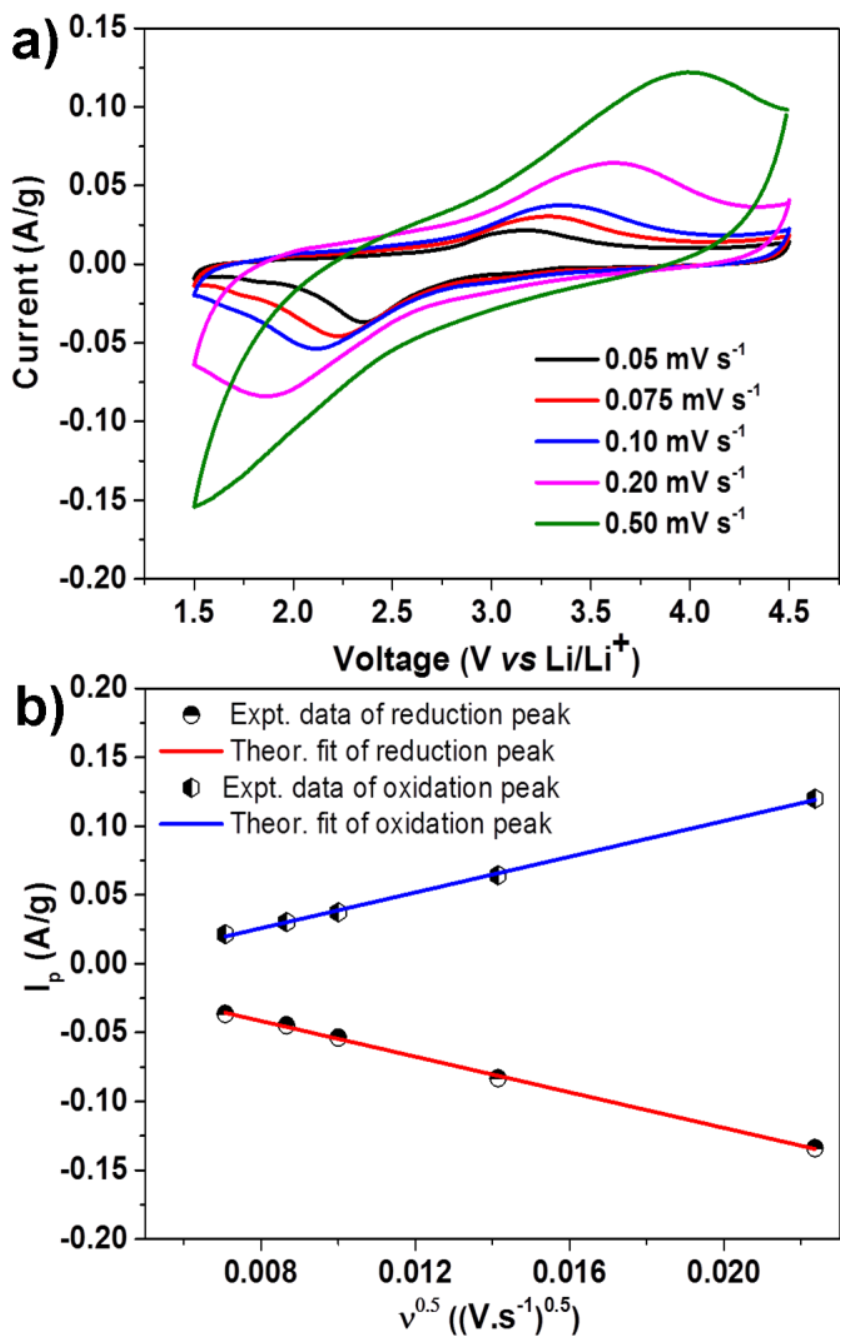
Figure 5. (a) $\mathrm{CV}$ profiles of $\mathrm{LiFeBO}_{3}$ with various scan rates (b) Graphs of the $\mathrm{LiFeBO}_{3}$ with normalized peak current $v s$ square root of the scan rate.

\section{Structural analysis}

To study structural changes post mortem analyses using ex-situ XRD and Mössbauer spectroscopy transmission electron microscopy measurements have been performed for pristine, charged and charged-discharged samples. According to $\mathrm{XRD}$, the $\mathrm{LiFeBO}_{3}$ lattice volume contracts by $19 \%$ on charging due to the removal of $\mathrm{Li}$-ions from the $\mathrm{LiFeBO}_{3}$ host structure, comparable with the value of $20 \%(0.15<x<1)$ found by Yamada et al. ${ }^{19}$ The structure was maintained during the charge-discharge which is a precondition for high reversibility of the process. All major reflections in the XRD pattern were present for the monoclinic structure (ICSD \#94317), see Figure 6 a). It is interesting to note that the martensitic Fe-C solid solution with low carbon content impurity (1.7(3) wt. \%) was partially oxidised to $\mathrm{Fe}^{2+}$ or $\mathrm{Fe}^{3+}$ during first charge as evidenced by Mössbauer spectroscopy. The amount of cementite phase, $\mathrm{Fe}_{3} \mathrm{C}$ was not affected by the discharge

process and was constant in subsequent cycles. ${ }^{28}$ Figure $6 \mathrm{~b}$ shows the $\mathrm{Fe}-\mathrm{L}_{3}$ edges of the EELS spectrum $(705-715 \mathrm{eV})$ of the charged state and the as-prepared sample. $1.0 \mathrm{eV}$ blue-shift of the charged state with respect to the as-prepared sample indicates an increase of iron valance state in the de-lithiated sample after charging. An overlay of the selected area electron diffraction profiles of the charged state and the discharged state can be seen in figure $6 \mathrm{c}$ ), where, revealing the expected $1 \%$ shift to higher angles for the charged state compared to the as-prepared sample, indicating the lattice contraction after $\mathrm{Li}^{+}$deintercalation. Supporting information shows the study of beam damage of $\mathrm{LiFeBO}_{3}$ in HRTEM (Figure S3) and SAED (Figure S4) leading to amorphization. 

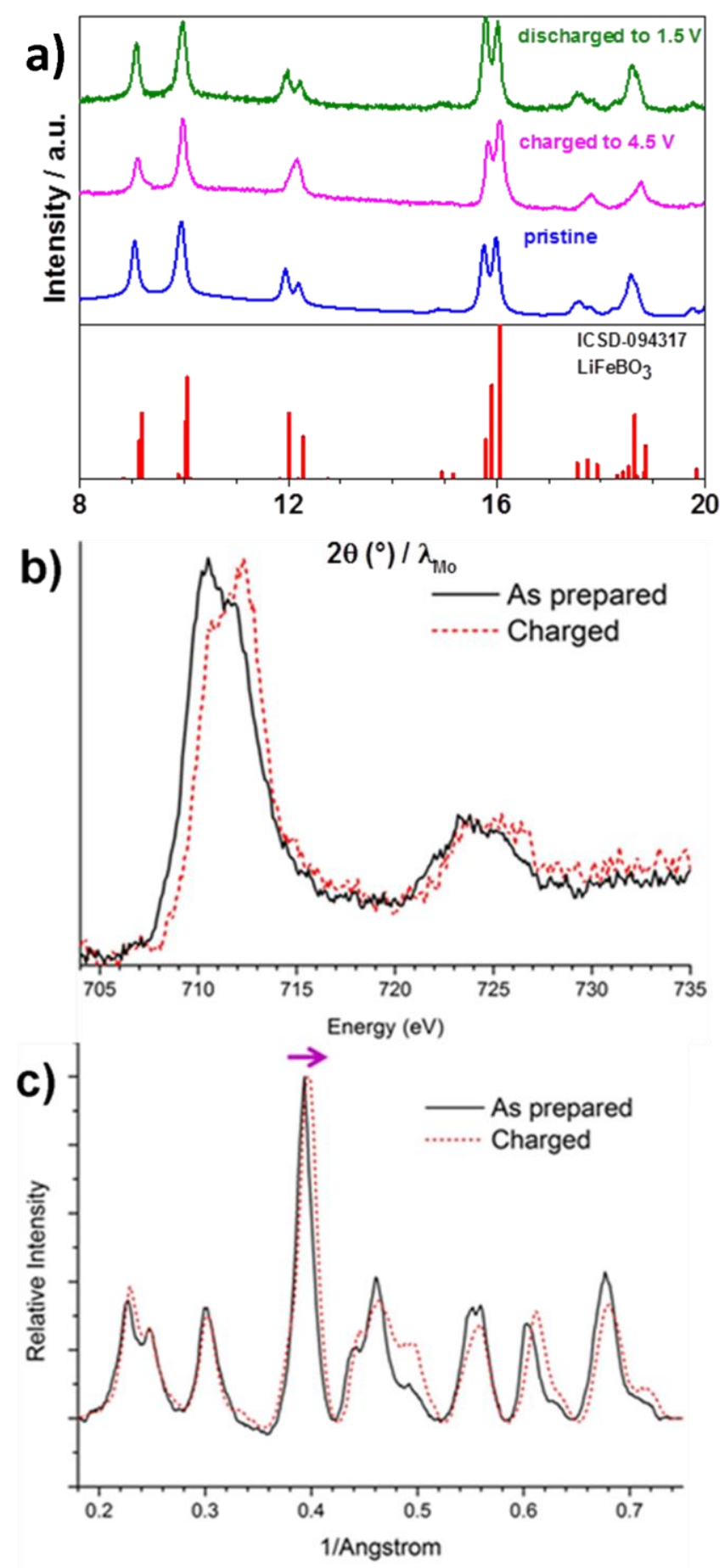

Figure 6. (a) Ex-situ XRD patterns of $\mathrm{LiFeBO}_{3}$ in discharged, charged and as prepared state (b) EELS spectra of the Fe- $\mathrm{L}_{3,2}$ edges of the as-prepared (black, solid line) and charged (red, dashed line) samples. c) Electron diffraction profiles of the as prepared (black, solid line) and charged (red, dashed line) samples. 
The ${ }^{57} \mathrm{Fe}$ Mössbauer spectra of the as prepared, charged and discharged sample are presented in figure $1 \mathrm{~b}$ ) and $7 \mathrm{a}$ )-b) respectively, the results of the fitting procedure are summarized in table $\mathrm{S} 1$. Upon charging the material, $\mathrm{Fe}^{2+}$ gets partly oxidized as evidenced by the presence of a doublet with typical ferric $I S$ in the spectrum. This can be attributed to the charge compensation. When removing the $\mathrm{Li}^{+}$from the $\mathrm{LiFeBO} \mathrm{B}_{3}$ lattice, about $70 \%$ of the $\mathrm{Fe}^{2+}$ ions were oxidised (although the relative area ratios given cannot be compared between the different structural phases, it is possible to compare the $\mathrm{Fe}^{2+} / \mathrm{Fe}^{3+}$ ratio as the ions occupy the same lattice site in the $\mathrm{LiFeBO}_{3}$ host structure, having virtually the same Debye-Waller factor). The $I S$ and $Q S$ of the remaining ferrous Fe were both increased, compared to the pristine sample. The extraction of Li-ions and the associated charge re-distribution is changing the electric field gradient on the site of the $\mathrm{Fe}^{2+}$ ions. In the spectra presented by Yamada et al. ${ }^{19}$ a similar behaviour was observed for an air exposed and therefore oxidised $\mathrm{LiFeBO}_{3}$ compound. The sextets from the martensitic Fe-C disappeared from the spectrum. Thus, it can be assumed that the metallic $\mathrm{Fe}$ atoms get oxidised and their corresponding spectral area (in form of a doublet overlaps with the broad $\mathrm{Fe}^{3+}$ doublet. The $\mathrm{F}_{3} \mathrm{C}$ phase remains basically unchanged and stable at this electrochemical potential.

Discharging the sample partly reduces $\mathrm{Fe}^{3+}$ to $\mathrm{Fe}^{2+}$, which could be recovered to about $70 \%$ of the initial spectral area. $I S$ and $Q S$ of the $\mathrm{Fe}^{2+}$ species were decreased, compared to the charged state, but still higher than in the pristine sample, which is a proof for the remaining distortion of the electric field gradient due to the $\mathrm{Fe}^{3+}$ ions in the lattice. This is in perfect agreement with the residual lattice contraction observed by XRD. The martensitic Fe-C phase recovers nearly fully after discharging the sample. 


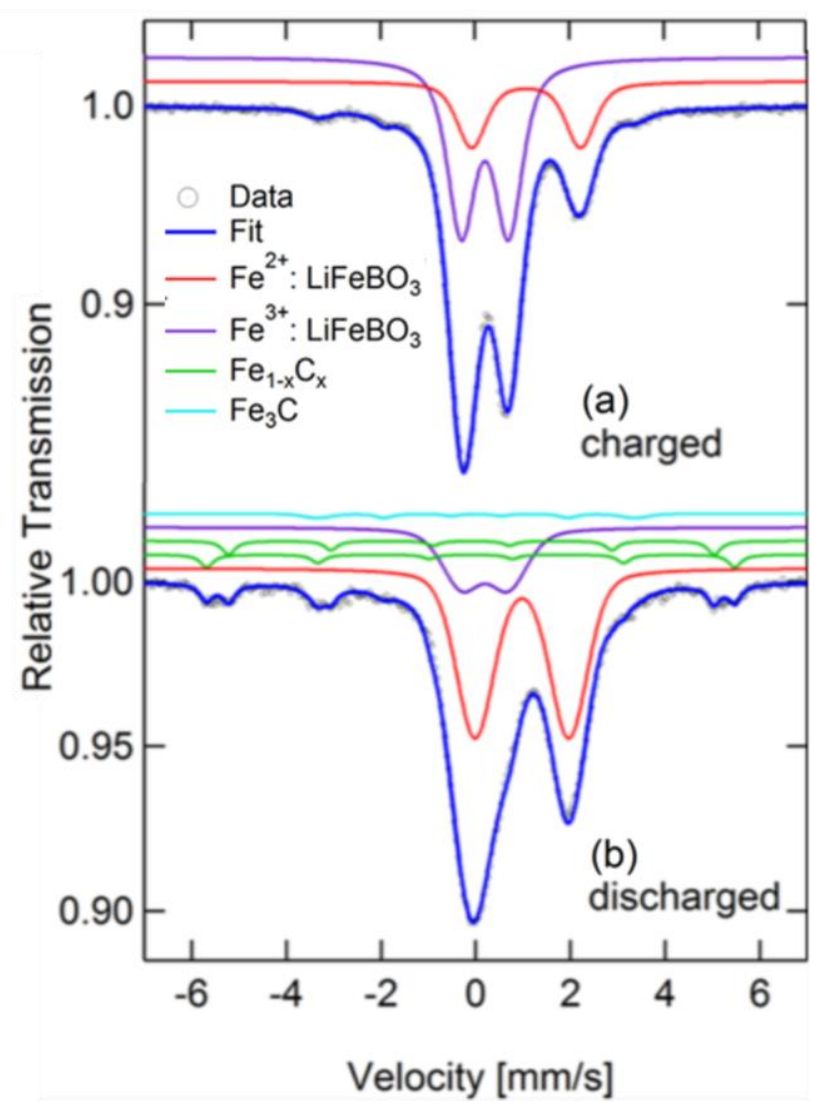

Figure 7. Mössbauer spectra of the charged and discharged sample respectively (a) and (b). Two quadrupole doublets are attributed to the $\mathrm{Fe}^{2+} / \mathrm{Fe}^{3+}$ species in the $\mathrm{Li}_{1-\mathrm{y}} \mathrm{FeBO}_{3}$ structure, the three sextets are assigned to various Fe-C compounds, see text for details.

The practical energy density of various iron based polyanionic compounds are compared with our $\mathrm{LiFeBO} 3$ results in figure 8. In relation to the other polyanionic cathodes LiFeBO3 offers a possibility to achieve higher energy densities. Performance wise it's still immature and has not been optimised. 


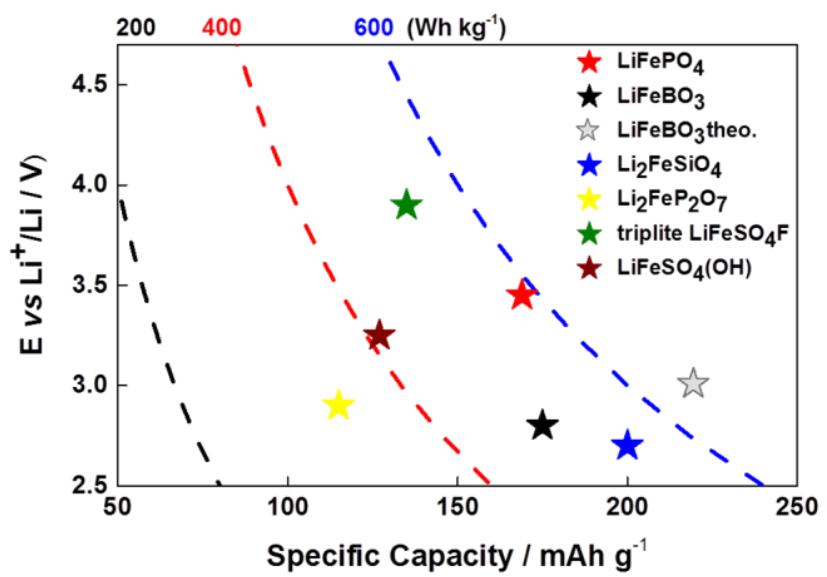

Figure 8. Practical specific capacity, voltage and energy density for different iron based polyanionic compounds for lithium ion batteries. ${ }^{2,4}$

\section{Conclusion}

This report provides a new strategy for synthesizing high performance $\mathrm{LiFeBO}_{3}$, which tends to have significant performance limitations depending on the synthesis conditions. Using $\mathrm{FeO}$ as iron precursors helps to obtain $\mathrm{LiFeBO}_{3}$ with higher purity. Additionally we are providing lithium diffusion coefficients in the magnitude of $5.56 \times 10^{-14} \mathrm{~cm}^{2} \mathrm{~s}^{-1}$ for the $\mathrm{LiFeBO}_{3}$ carbon composite, which are implying slow kinetics. Further improvement of the electrochemical characteristics may be possible by further downsizing and optimization of the ball milling and heating conditions. Furthermore the method described herein is versatile and could be applied for the synthesis of $\mathrm{LiMBO}_{3} \mathrm{M}=\mathrm{Zn}, \mathrm{Mg}, \mathrm{Mn}, \mathrm{Co}$.

\section{Acknowledgement}

Financial support by EU-RTD "Hi-C" (Novel in situ and in operando techniques for characterization of interfaces in electrochemical storage systems") in the $7^{\text {th }} \mathrm{FP}$, grant agreement no. 608575 is gratefully acknowledged. The authors acknowledge the support by the Karlsruhe Nano Micro Facility (KNMF) for the access to the electron microscopy and spectroscopy facilities. C.V and X.M. thank Prof. Dr. Horst Hahn for his continuous support.

\section{References}

(1) Padhi, A. K.; Nanjundaswamy, K. S.; Goodenough, J. B. D. Phospho-Olivines as Positive-Electrode Materials for Rechargeable Lithium Batteries. J. Electrochem. Soc. 1997, 144, 2-8. 
(2) Masquelier, C.; Croguennec, L. Polyanionic (phosphates, Silicates, Sulfates) Frameworks as Electrode Materials for Rechargeable Li (or Na) Batteries. Chem. Rev. 2013, 113, 6552-6591.

(3) Gutierrez, A.; Benedek, N. A.; Manthiram, A. Crystal-Chemical Guide for Understanding Redox Energy Variations of M 2+/3+ Couples in Polyanion Cathodes for Lithium-Ion Batteries. Chem. Mater. 2013, 25, 4010-4016.

(4) Rousse, G.; Tarascon, J. M. Sulfate-Based Polyanionic Compounds for Li-Ion Batteries: Synthesis, Crystal Chemistry, and Electrochemistry Aspects. Chem. Mater. 2014, 26, 394-406.

(5) Bo, S. H.; Veith, G. M.; Saccomanno, M. R.; Huang, H.; Burmistrova, P. V.; Malingowski, A. C.; Sacci, R. L.; Kittilstved, K. R.; Grey, C. P.; Khalifah, P. G. Thin-Film and Bulk Investigations of LiCoBO3 as a Li-Ion Battery Cathode. ACS Appl. Mater. Interfaces 2014, 6, 10840-10848.

(6) Afyon, S.; Mensing, C.; Krumeich, F.; Nesper, R. The Electrochemical Activity for Nano-LiCoBO3 as a Cathode Material for Li-Ion Batteries. Solid State lonics 2014, 256, 103-108.

(7) Kaliyappan, K.; Amaresh, S.; Lee, Y.-S. $\mathrm{LiMnBO}_{3}$ Nanobeads as an Innovative Anode Material for High Power Lithium Ion Capacitor Applications. ACS Appl. Mater. Interfaces 2014, 6, 1135711367.

(8) Kim, J. C.; Seo, D.-H.; Ceder, G. Theoretical Capacity Achieved in a LiMn 0.5 Fe 0.4 Mg 0.1 BO 3 Cathode by Using Topological Disorder. Energy Environ. Sci. 2015, 8, 1790-1798.

(9) Janssen, Y.; Middlemiss, D. S.; Bo, S. H.; Grey, C. P.; Khalifah, P. G. Structural Modulation in the High Capacity Battery Cathode Material LiFeBO 3. J. Am. Chem. Soc. 2012, 134, 12516-12527.

(10) Malik, R.; Abdellahi, A.; Ceder, G. A Critical Review of the Li Insertion Mechanisms in LiFePO4 Electrodes. J. Electrochem. Soc. 2013, 160, A3179-A3197.

(11) Barpanda, P.; Dwibedi, D.; Ghosh, S.; Kee, Y.; Okada, S. Lithium Metal Borate (LiMBO3) Family of Insertion Materials for Li-Ion Batteries: A Sneak Peak. Ionics (Kiel). 2015, 21, 1801-1812.

(12) Malik, R.; Burch, D.; Bazant, M.; Ceder, G. Particle Size Dependence of the Ionic Diffusivity. Nano Lett. 2010, 10, 4123-4127.

(13) Seo, D.-H.; Park, Y.-U.; Kim, S.-W.; Park, I.; Shakoor, R.; Kang, K. First-Principles Study on Lithium Metal Borate Cathodes for Lithium Rechargeable Batteries. Phys. Rev. B 2011, 83, 1-8.

(14) Kim, J. C.; Seo, D.-H.; Chen, H.; Ceder, G. The Effect of Antisite Disorder and Particle Size on Li Intercalation Kinetics in Monoclinic LiMnBO3. Adv. Energy Mater. 2015, 5,: 1401916. doi: 10.1002/aenm.201401916

(15) Legagneur, V. LiMBO3 (M=Mn, Fe, Co): Synthesis, Crystal Structure and Lithium Deinsertion/insertion Properties. Solid State Ionics, 2001, 139, 37-46.

(16) Abouimrane, A.; Armand, M.; Ravet, N. Carbon Nano-Painting: Application to Non-Phosphate Oxyanions, e.g. Borates. Proc. - Electrochem. Soc., 2003, 2003-20, 15.

(17) Dong, Y. Z.; Zhao, Y. M.; Shi, Z. D.; An, X. N.; Fu, P.; Chen, L. The Structure and Electrochemical Performance of LiFeBO3 as a Novel Li-Battery Cathode Material. Electrochim. Acta 2008, 53, 2339-2345.

(18) Allen, J. L.; Xu, K.; Zhang, S. S.; Jow, T. R. LiMBO3 (M=Fe, Mn): Potential Cathode for Lithium lon Batteries. Mater. Res. Soc. Symp. Proc., 2002, 730, 9-14.

Yamada, A.; Lwane, N.; Harada, Y.; Nishimura, S. I.; Koyama, Y.; Tanaka, L. Lithium Iron Borates as 
High-Capacity Battery Electrodes. Adv. Mater. 2010, 22, 3583-3587.

(20) Bo, S.-H.; Wang, F.; Janssen, Y.; Zeng, D.; Nam, K.-W.; Xu, W.; Du, L.-S.; Graetz, J.; Yang, X.-Q.; Zhu, Y.; et al. Degradation and (de)lithiation Processes in the High Capacity Battery Material LiFeBO3. J. Mater. Chem. 2012, 22, 8799-8809.

(21) Tao, L.; Rousse, G.; Chotard, J. N.; Dupont, L.; Bruyère, S.; Hanžel, D.; Mali, G.; Dominko, R.; Levasseur, S.; Masquelier, C. Preparation, Structure and Electrochemistry of LiFeBO3: A Cathode Material for Li-Ion Batteries. J. Mater. Chem. A, 2014, 2, 2060-2070.

(22) Tao, L.; Neilson, J. R.; Melot, B. C.; McQueen, T. M.; Masquelier, C.; Rousse, G. Magnetic Structures of LiMBO3 ( $\mathrm{M}=\mathrm{Mn}, \mathrm{Fe}, \mathrm{Co}$ ) Lithiated Transition Metal Borates. Inorg. Chem. 2013, 52, 11966-11974.

(23) Barpanda, P.; Yamashita, Y.; Yamada, Y.; Yamada, A. High-Throughput Solution Combustion Synthesis of High-Capacity LiFeBO3 Cathode. J. Electrochem. Soc. 2013, 160, A3095-A3099.

(24) Zhang, B.; Ming, L.; Zheng, J.; Zhang, J.; Shen, C.; Han, Y.; Wang, J.; Qin, S. Synthesis and Characterization of Multi-Layer Core-Shell Structural LiFeBO3/C as a Novel Li-Battery Cathode Material. J. Power Sources 2014, 261, 249-254.

(25) Brauer, G. Handbook of Preparative Inorganic Chemistry; 2nd ed.; Academic Press, 1965.

(26) Le Caër, G.; Matteazzi, P. Mössbauer Study of Mechanosynthesized Iron Carbides. Hyperfine Interact. 1991, 66, 309-317.

(27) Kang, S.-H.; Goodenough, J. B.; Rabenberg, L. K. Effect of Ball-Milling on 3-V Capacity of Lithium-Manganese Oxospinel Cathodes. Chem. Mater. 2001, 13, 1758-1764.

(28) Bo, S. H.; Nam, K. W.; Borkiewicz, O. J.; Hu, Y. Y.; Yang, X. Q.; Chupas, P. J.; Chapman, K. W.; Wu, L.; Zhang, L.; Wang, F.; et al. Structures of Delithiated and Degraded LiFeBO3, and Their Distinct Changes upon Electrochemical Cycling. Inorg. Chem. 2014, 53, 6585-6595.

(29) Augustyn, V.; Come, J.; Lowe, M. a; Kim, J. W.; Taberna, P.-L.; Tolbert, S. H.; Abruña, H. D.; Simon, P.; Dunn, B. High-Rate Electrochemical Energy Storage through Li+ Intercalation Pseudocapacitance. Nat. Mater. 2013, 12, 518-522.

(30) Zhou, N.; Wang, H.-Y.; Uchaker, E.; Zhang, M.; Liu, S.-Q.; Liu, Y.-N.; Cao, G. Additive-Free Solvothermal Synthesis and Li-Ion Intercalation Properties of Dumbbell-Shaped LiFePO4/C Mesocrystals. J. Power Sources 2013, 239, 103-110.

(31) Zheng, Z.; Wang, Y.; Zhang, A.; Zhang, T.; Cheng, F.; Tao, Z.; Chen, J. Porous Li2FeSiO4/C Nanocomposite as the Cathode Material of Lithium-Ion Batteries. J. Power Sources 2012, 198, 229-235.

\section{Associated Content}

\section{Supporting Information:}

Fit results Mössbauer spectra, SEM, BET, beam sensitivity study with HRTEM and SAED 
"This material is available free of charge via the Internet at http://pubs.acs.org."

Table of Contents graphic

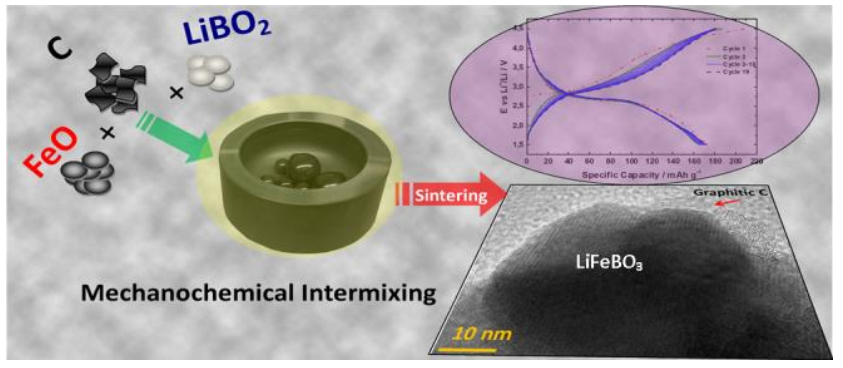

